\title{
A Novel Inhibitor of STAT5 Signaling Overcomes Chemotherapy Resistance in Myeloid Leukemia Cells
}

\author{
Marie Brachet-Botineau ${ }^{1}$, Margaux Deynoux ${ }^{1}$, Nicolas Vallet ${ }^{1,2}$, Marion Polomski ${ }^{3}$,

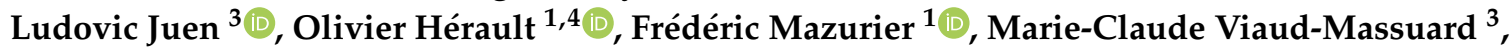 \\ Gildas Prié ${ }^{3}$ iD and Fabrice Gouilleux ${ }^{1, *(D)}$ \\ 1 LNOx, GICC, CNRS ERL 7001, University of Tours, 37000 Tours, France; marie.brachet@univ-tours.fr (M.B.-B.); \\ margaux.deynoux@etu.univ-tours.fr (M.D.); nls.vallet@gmail.com (N.V.); olivier.herault@univ-tours.fr (O.H.); \\ frederic.mazurier@inserm.fr (F.M.) \\ 2 Service d'Hématologie et Thérapie Cellulaire, CHRU de Tours, 37000 Tours, France \\ 3 IMT, GICC, EA 7501, University of Tours, 37000 Tours, France; marion.polomski@etu.univ-tours.fr (M.P.); \\ ludovic.juen@mcsaf.fr (L.J.); marie-claude.viaud-massuard@univ-tours.fr (M.-C.V.-M.); \\ gildas.prie@univ-tours.fr (G.P.) \\ 4 Service d'Hematologie Biologique, CHRU de Tours, 37000 Tours, France \\ * Correspondence: fabrice.gouilleux@univ-tours.fr; Tel.: +33-(2)-47-36-62-91
}

Received: 8 August 2019; Accepted: 14 December 2019; Published: 17 December 2019

check for updates

\begin{abstract}
Signal transducers and activators of transcription 5A and 5B (STAT5A and STAT5B) are crucial downstream effectors of tyrosine kinase oncogenes (TKO) such as BCR-ABL in chronic myeloid leukemia (CML) and FLT3-ITD in acute myeloid leukemia (AML). Both proteins have been shown to promote the resistance of CML cells to tyrosine kinase inhibitors (TKI) such as imatinib mesylate (IM). We recently synthesized and discovered a new inhibitor (17f) with promising antileukemic activity. $17 \mathrm{f} \mathrm{selectively} \mathrm{inhibits} \mathrm{STAT5} \mathrm{signaling} \mathrm{in} \mathrm{CML} \mathrm{and} \mathrm{AML} \mathrm{cells} \mathrm{by} \mathrm{interfering} \mathrm{with} \mathrm{the} \mathrm{phosphorylation}$ and transcriptional activity of these proteins. In this study, the effects of $17 \mathrm{f}$ were evaluated on CML and AML cell lines that respectively acquired resistance to IM and cytarabine (Ara-C), a conventional therapeutic agent used in AML treatment. We showed that $17 \mathrm{f}$ strongly inhibits the growth and survival of resistant CML and AML cells when associated with IM or Ara-C. We also obtained evidence that $17 \mathrm{f}$ inhibits STAT5B but not STAT5A protein expression in resistant CML and AML cells. Furthermore, we demonstrated that $17 \mathrm{f}$ also targets oncogenic STAT5B N642H mutant in transformed hematopoietic cells.
\end{abstract}

Keywords: pharmacological inhibitor; STAT5 signaling; chemotherapy resistance; myeloid leukemia

\section{Introduction}

STAT5A and STAT5B are two closely related signal transducers and activators of transcription family members. Both proteins are crucial downstream effectors of tyrosine kinase oncogenes (TKO) such as Fms-like receptor tyrosine kinase 3 with internal tandem duplications (Flt3-ITD), BCR-ABL and JAK2 ${ }^{\mathrm{V} 617 \mathrm{~F}}$ which cause AML, CML and other myeloproliferative diseases (MPD), respectively [1]. STAT5 proteins are recognized as major drivers in the development and/or maintenance of CML as well as in the proliferation and survival of AML cells [2-4]. The development of tyrosine kinase inhibitors (TKI) targeting BCR-ABL such as imatinib mesylate (IM) has revolutionized the treatment of CML. Despite this success story, IM is not totally curative and approximately $50 \%$ of patients remain therapy-free after IM discontinuation. The inability of IM to completely eradicate leukemic stem cells (LSC) is probably responsible for the relapse of CML patients [5]. Moreover, the occurrence of $B C R-A B L$ mutations in progressive or relapsed disease promotes IM resistance of CML cells [6]. 
Therefore, there is a need for complementary therapeutic strategies to cure CML. STAT5 fulfils all the criteria of a major drug target in CML [7]. High STAT5 expression levels have been shown not only to enhance IM resistance in CML cells but also to trigger $B C R-A B L$ mutations by inducing the production of reactive oxygen species (ROS) responsible for DNA damage [8,9]. Moreover, STAT5 was shown to play a key role in the maintenance of chemoresistant CML stem cells [10]. Thus, targeting STAT5 would also benefit relapsed CML patients who became resistant to TKI. Several approaches have been used to target STAT5 in leukemia. Among them, cell-based screening with small molecule libraries of already approved drugs allowed the identification of the psychotropic drug pimozide as a potential STAT5 inhibitor in CML cells [11]. Pimozide decreased the tyrosine phosphorylation of STAT5 and induced growth arrest and apoptosis in CML cells. In addition, pimozide was shown to target the deubiquitinating (DUB) enzyme, USP1, in leukemic cells indicating that the effects of pimozide on STAT5 activity might be indirect [12]. Indirubin derivatives were also reported to inhibit STAT5 phosphorylation in CML cells but the mechanism of inhibition is most likely suppression of upstream tyrosine kinases [13]. More recently, a number of small inhibitors that bind to the Src homology domain $2\left(\mathrm{SH}_{2}\right)$ required for STAT5 activation and dimer formation, have been described [14]. These compounds exhibit potent and selective binding activity for STAT5 by effectively disrupting phosphopeptide interactions. Some of these inhibitors bind STAT5 proteins in a nanomolar range and inhibit the tyrosine phosphorylation of STAT5 and CML/AML cell growth in a micromolar range [15-17]. A final approach is to target STAT5 activity through the activation of peroxisome proliferator-activated receptor gamma (PPAR $\gamma$ ) [18]. Indeed, the existence of cross-talk between PPAR $\gamma$ and STAT5 has been discussed. For instance, antidiabetic drugs such as glitazones, which are PPAR $\gamma$ agonists, were shown to have antileukemic activity $[19,20]$. Activation of PPAR $\gamma$ by pioglitazone not only decreases the phosphorylation of STAT5 in CML cells but also reduces expression of STAT5 genes in quiescent and resistant CML stem cells [10]. Importantly, the combined use of pioglitazone and IM triggers apoptosis of these leukemic cells suggesting that besides phosphorylation, inhibition of STAT5 expression is of prime importance for resistant CML stem cell eradication. Based on these different data, we sought to identify new STAT5 inhibitors in a library of PPAR $\alpha / \gamma$ ligands that were synthetized in our laboratory [21,22]. The synthesis of derivatives of a "hit" compound identified in the library screening allowed the discovery of a new inhibitor of STAT5 signaling in CML and AML cells [23]. This molecule (17f) selectively inhibits the phosphorylation and transcriptional activity of STAT5 and induces apoptosis of CML and AML cells. Herein, we showed that $17 \mathrm{f}$ associated with IM or Ara-C resensitizes CML and AML cells, respectively, that acquired resistance to these drugs. We demonstrated that $17 \mathrm{f}$ treatment reduces STAT5B protein levels in resistant CML and AML cells, suggesting that $17 \mathrm{f}$ overcomes chemotherapy resistance though the downregulation of this protein. We also found that $17 \mathrm{f}$ suppresses expression of oncogenic STAT5 ${ }^{\mathrm{N} 642 \mathrm{H}}$ mutant in transformed $\mathrm{Ba} / \mathrm{F} 3$ cells.

\section{Results}

\subsection{Effects of $17 f$ Compound on Growth and Viability of IM-Sensitive and IM-Resistant BCR-ABL $L^{+}$Cells}

Initial experiments were carried out to determine the effects of $17 \mathrm{f}$ alone (see structure in Figure S1) on K562 cells that are sensitive (K562S) or resistant (K562R) to IM treatment. These in vitro models are depicted in Figure 1A. Sensitive and resistant cells were treated with various concentrations of $17 \mathrm{f}$ (ranging from 1 to $10 \mu \mathrm{M}$ ). Growth and viability were determined by trypan blue exclusion (Figure 1B) and MTT (3-(4,5-dimethylthiazol-2-yl)-2,5-diphenyltetrazolium bromide) (Figure 1C) assays. Addition of $17 \mathrm{f}$ clearly blocked the growth of $\mathrm{K} 562 \mathrm{~S}$ cells while $\mathrm{K} 562 \mathrm{R}$ cells remain insensitive to $17 \mathrm{f}$ treatment at the same concentration. The $\mathrm{EC}_{50}$ value was found to be two times higher in $\mathrm{K} 562 \mathrm{R}$ cells than in $\mathrm{K} 562 \mathrm{~S}$ cells $(14.5 \pm 4.8 \mu \mathrm{M}$ vs. $6.9 \pm 1.7 \mu \mathrm{M})$. We also observed that treatment with $5 \mu \mathrm{M} 17 \mathrm{f}$ did not affect the growth and viability of K562R cells and used this suboptimal concentration in most experiments to evaluate the combined effects of $17 \mathrm{f}$ and IM. 
A
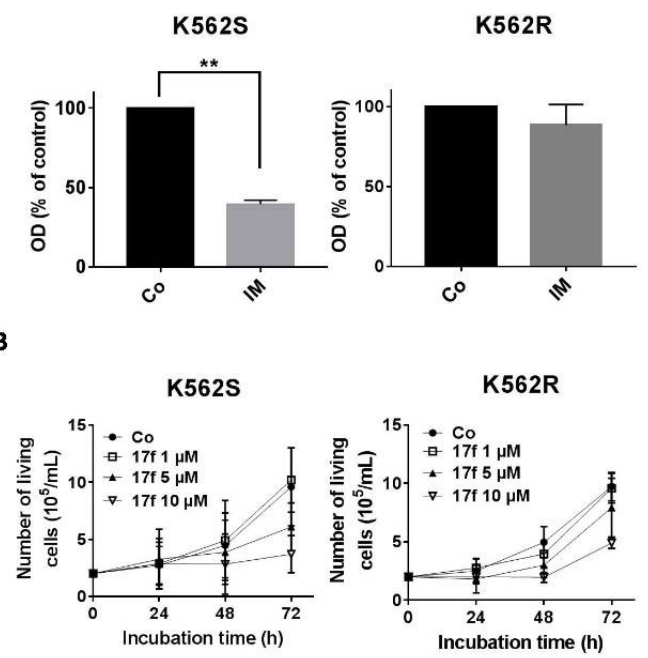

c

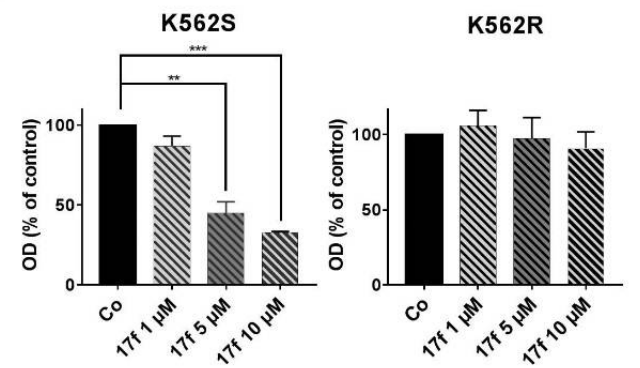

Figure 1. Effects of $17 \mathrm{f}$ molecule on $\mathrm{K} 562 \mathrm{~S}$ and $\mathrm{K} 562 \mathrm{R}$ cell growth (A) Imatinib mesylate (IM)-sensitive K562 (K562S) and IM-resistant K562 cells (K562R) were treated with $1 \mu \mathrm{M}$ IM or DMSO as control (Co) for $48 \mathrm{~h}$. Cell viability was determined by MTT assays (data are presented as mean \pm SD of three independent experiments $(n=3)$ in triplicates, ${ }^{* * *} p<0.001$; one sample $t$-test). (B) K562S and K562R cells were treated with $17 \mathrm{f}$ or DMSO as control (Co) for the indicated times. Growth kinetics were determined by trypan blue dye exclusion assays ( $n=3$ in triplicates, data are mean \pm SD). (C) Cell viability was measured by MTT assays after treatment of K562S or K562R cells with increasing concentrations of $17 \mathrm{f}$ or DMSO as control (Co) during $48 \mathrm{~h}$ ( $n=3$ in triplicates, data are mean \pm SD, ** $p<0.01,{ }^{* * *} p<0.001$; one sample $t$-test).

\section{2. $17 f$ Induces Apoptosis and Cell Cycle Arrest in K562R Cells and Relieves the Resistance to IM}

We then addressed whether $17 \mathrm{f}$ in combination with IM might directly abrogate the resistance of K562R cells to IM. K562S and K562R cells were treated with $17 \mathrm{f}$ in the presence of IM and cell growth and viability were determined by MTT assays (Figure 2A). As expected, IM strongly inhibited the growth of K562S cells. This inhibition was further enhanced by $17 \mathrm{f}$ in a dose-dependent fashion. Interestingly, we found that the addition of $1 \mu \mathrm{M} 17 \mathrm{f}$ in the presence of IM was already enough to significantly reduce the growth and viability of K562R cells. Treatment with $5 \mu \mathrm{M}$ and $10 \mu \mathrm{M}$ of $17 \mathrm{f}$ further increased this inhibitory effect. To analyze the growth-suppressive properties of $17 \mathrm{f}$ in $\mathrm{K} 562 \mathrm{R}$ cells, we determined the impact of this small molecule on apoptosis and the cell cycle. 17f induced apoptosis and changes in cell cycle phase distribution in a concentration-dependent manner (Figure 2B,C). 17f significantly increased the number of cells in the $\mathrm{G}_{0}$ phase indicating that treatment with this compound induced quiescence of K562R cells. 
A

K562S

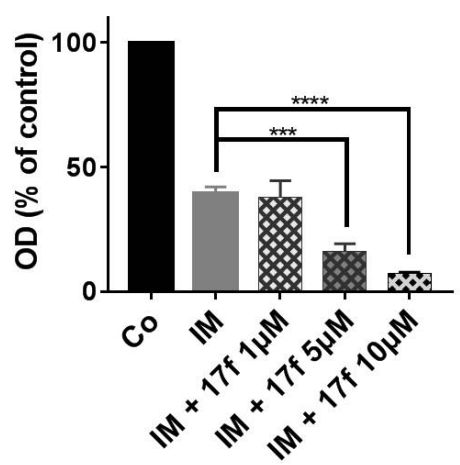

B

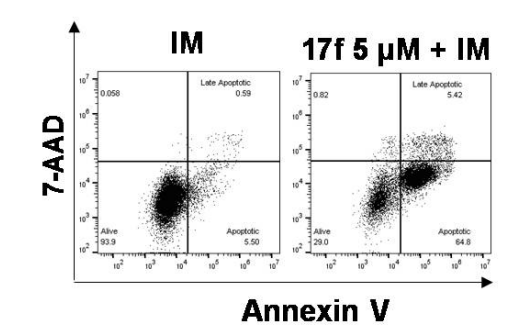

C

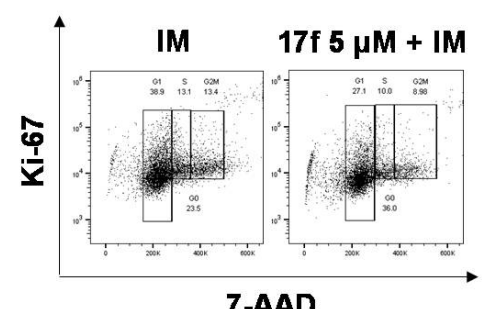

K562R

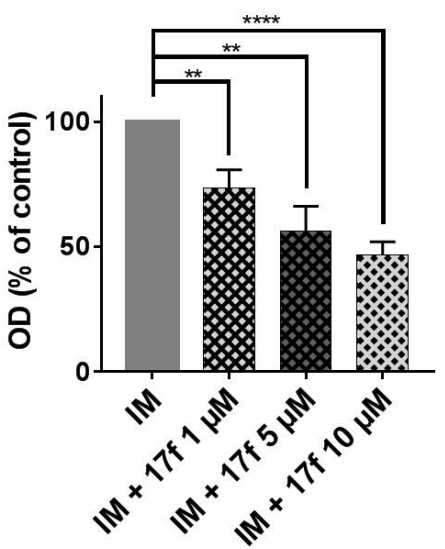

K562R

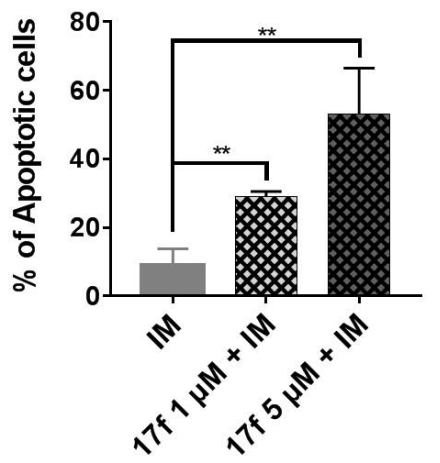

K562R

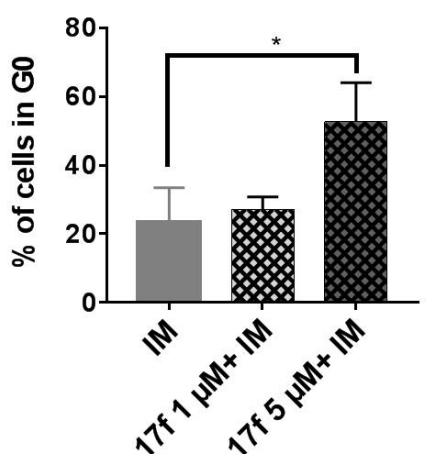

Figure 2. 17f overcomes the resistance of K562R cells to IM treatment. (A) K562S and K562R cells were treated with IM or not (Co) with or without $17 \mathrm{f}$ for $48 \mathrm{~h}$. Cell viability was determined by MTT assays. (B) K562R cells cultured for $48 \mathrm{~h}$ with IM and $17 \mathrm{f}$ or IM vs. DMSO as control. Cells were stained with anti-annexin V coupled with FITC (fluorescein isothiocyanate) and with 7-amino-actinomycin $\mathrm{D}$ (7-AAD) to determine the percentages of apoptotic cells. One representative experiment is shown (left panel). (C) K562R cells treated for $48 \mathrm{~h}$ with IM and $17 \mathrm{f}$ or IM and DMSO as control were stained with 7-AAD and an Alexa Fluor 488-conjugated anti-Ki-67 antibody. Cell cycle phase distributions were then estimated by flow cytometry. The histogram presents the percentage of cells in the $\mathrm{G}_{0}$ phase. One representative experiment is shown (left panel) $(n=3$ in triplicates, data are mean $\pm \mathrm{SD}, * p<0.05$, $\left.* * p<0.01,{ }^{* * *} p<0.001, * * * * 0.0001\right)$. 


\section{3. $17 f$ Inhibits STAT5-Dependent Transcriptional Activity in K562R Cells}

We previously showed that $17 \mathrm{f}$ inhibits the transcriptional activity of STAT5 in CML cells. We then asked whether this small molecule also affects the activity of these proteins in IM-resistant K562R cells. We first determined the impact of this compound on the transcriptional activation of a reporter gene driven by a STAT5-specific promoter. K562S and K562R cells were transfected with a construct containing six tandem copies of the STAT5 response element in front of the minimal TK promoter fused to the luciferase reporter gene (6×(STAT5)-TK-luc). As control, cells were also transfected with a TK-luciferase vector without STAT5 response elements (TK-luc). Luciferase activity was determined $48 \mathrm{~h}$ post-transfection in K562S and K562R cells treated with DMSO as control, $17 \mathrm{f}(5 \mu \mathrm{M})$ and/or IM $(1 \mu \mathrm{M})$. As expected, constitutive STAT5 activity induced by BCR-ABL increased luciferase activity in K562S cells transfected with the STAT5-dependent promoter construct compared to cells transfected with the control TK-luc vector (Figure 3A). This enhanced luciferase activity was strongly reduced after $17 \mathrm{f}$ or IM treatment. In sharp contrast, the luciferase activity remained elevated after treatment with IM in K562R cells transfected with the STAT5-dependent reporter construct, although this enzymatic activity was strongly decreased after the addition of $17 \mathrm{f}$ and IM. qRT-PCR experiments were then conducted to determine the effects of $17 \mathrm{f}$ on STAT5-dependent expression of target genes such as PIM1 and CISH (Figure 3B). As expected, 17f or IM reduced expression of both genes in sensitive K562S cells while this effect was observed in resistant K562R cells after treatment with both compounds. Collectively, these data strongly suggest that $17 \mathrm{f}$ inhibits the transcriptional activity of STAT 5 to bypass IM resistance in K562R cells.

\subsection{7f Inhibits STAT5B Protein Expression in IM-Resistant K562 Cells}

We then determined the impact of $17 \mathrm{f}$ on BCR-ABL-induced tyrosine phosphorylation of STAT5 (P-Y69/699-STAT5) by western blot and flow cytometry analysis (Figure 4A, Figures S2-S4). K562S and K562R cells were treated for $24 \mathrm{~h}$ instead of $48 \mathrm{~h}$ to analyze the early effects on STAT5 phosphorylation. IM strongly reduced P-Y-STAT5 levels in K562S, and the addition of $17 \mathrm{f}$ further enhanced this effect. P-Y-STAT5 levels were maintained in IM-treated K562R cells but were decreased after the addition of 17f. Interestingly, the level of STAT5 phosphorylation was strikingly enhanced in K562R cells after removal of IM and was weakly affected by the addition of $17 \mathrm{f}$ (Figure S5). To determine whether changes in P-Y-STAT5 levels reflect differences in protein abundance, immunoblots were performed with an anti-STAT5 antibody that recognizes STAT5A and STAT5B proteins (Figure 4B and Figure S2). As expected, IM inhibited the phosphorylation of STAT5 in sensitive and resistant cells. Interestingly, we observed that the association of $17 \mathrm{f}$ with IM reduces STAT5 expression in K562R cells but not in K562S cells (see Figure S3A,B for quantification). qRT-PCR experiments were then conducted to evaluate the impact of combination treatments on STAT5A and STAT5B gene expression in K562R cells. Results showed that $S T A T 5 A / 5 B$ mRNA levels were not affected by $17 \mathrm{f}$ when associated with IM (Figure 4B). In contrast, western blot analysis clearly evidenced that STAT5B protein expression was decreased after combination treatments suggesting that $17 \mathrm{f}$ sensitizes K562R cells to IM treatment by targeting STAT5B protein (Figure 4C). 
A
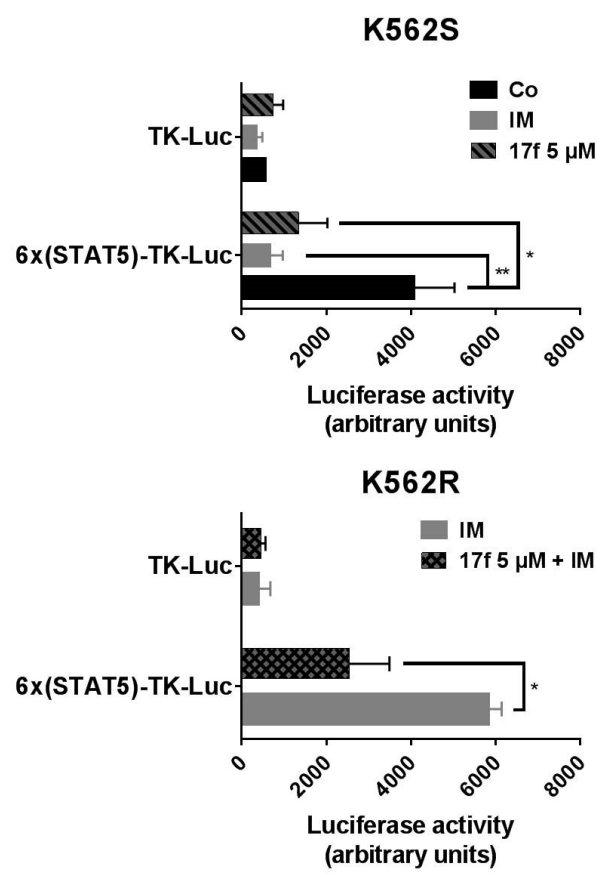

B

K562S

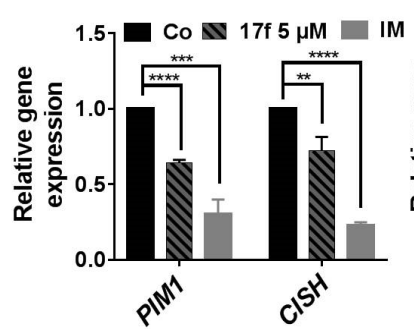

K562R

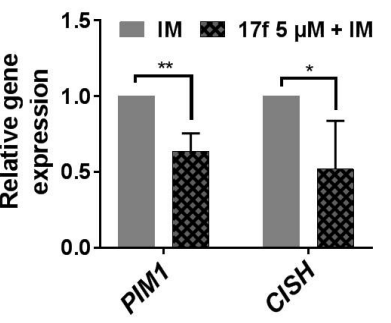

Figure 3. $17 \mathrm{f}$ associated with IM inhibit STAT5 activity in resistant K562R cells. (A) K562S or K562R cells transfected with a $6 \times($ STAT5)-TK-luciferase reporter construct or a control TK-luciferase vector were treated or not $(\mathrm{Co})$ with $17 \mathrm{f}(5 \mu \mathrm{M})$, IM $(1 \mu \mathrm{M})$ or with the combination of $17 \mathrm{f}$ and IM for $48 \mathrm{~h}$. Luciferase activities were then determined as described in Methods. Luciferase activity (arbitrary units) in the histogram represents the relative luminescence unit (rlu) values/mg of proteins $(n=3$ in triplicates, data are mean $\pm \mathrm{SD},{ }^{*} p<0.05,{ }^{* *} p<0.001$ ). (B) qRT-PCR analysis of PIM1 and CISH expression in K562S and K562R treated or not (Co) with IM $(1 \mu \mathrm{M}), 17 \mathrm{f}(5 \mu \mathrm{M})$ or with combined $17 \mathrm{f}$ and IM for $24 \mathrm{~h}$. Results are presented as the fold change in PIM1 and CISH gene expression in treated cells normalized to internal control genes (GAPDH, ACTB and RPL13a) and relative to control condition (normalized to 1) ( $n=3$ in triplicates, data are mean $\pm \mathrm{SD},{ }^{*} p<0.05$; one-sample $t$-test). 
A

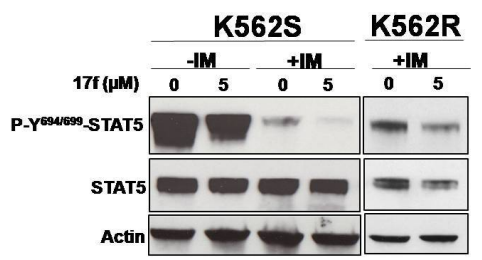

B

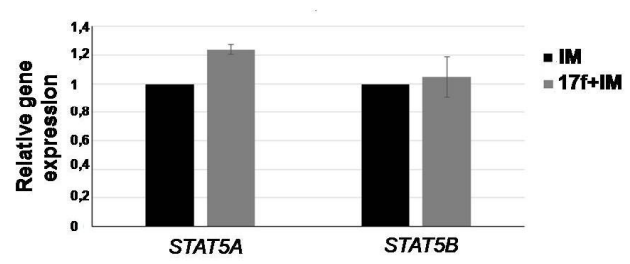

C
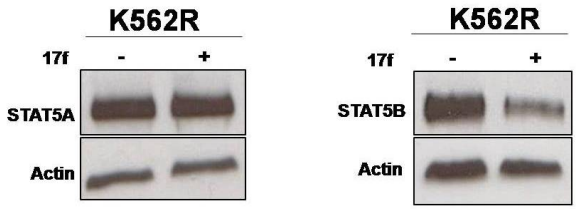

Figure 4. $17 \mathrm{f}$ associated with IM inhibits STAT5B protein expression in K562R cells (A) Protein extracts from K562S and K562R cells treated with 17f $5 \mu \mathrm{M}$ or DMSO with or without IM for $24 \mathrm{~h}$ were analyzed by western blotting to detect P-Y ${ }^{694 / 699}-$ STAT5 and STAT5 protein expression $(n=2)$. Actin served as the loading control. (B) qRT-PCR analysis of STAT5A and STAT5B expression in K562R cultured with IM $(1 \mu \mathrm{M})$ as control or treated with $17 \mathrm{f}(5 \mu \mathrm{M})$ and IM for $24 \mathrm{~h}$. Results are presented as the fold change in STAT5A and STAT5B gene expression in treated cells normalized to internal control genes (GAPDH, ACTB and RPL13a) and relative to control condition (normalized to 1 ) ( $n=3$ in triplicates, data are mean $\pm \mathrm{SD},{ }^{*} p<0.05$; one sample $t$-test). (C) Expression of STAT5A and STAT5B proteins in $\mathrm{K} 562 \mathrm{R}$ cells treated or not with $17 \mathrm{f}(5 \mu \mathrm{M})$ was analyzed by western blot $(n=2)$. Actin served as the loading control.

\subsection{Effects of $17 f$ on Growth and Viability of Ara-C-Sensitive and Ara-C-Resistant FLT3-ITD Expressing} Leukemic Cells

STAT5 is also phosphorylated by FLT3-ITD, a major TKO in AML cells. To exclude the possibility that $17 \mathrm{f}$-mediated inhibition of STAT5 and cell growth is a peculiarity of IM-resistant BCR-ABL ${ }^{+}$ cells, we used MV4-11 cells expressing FLT3-ITD that acquired resistance to Ara-C, a conventional therapeutic agent that affects DNA replication. Sensitive and resistant MV4-11 cell models are depicted in Figure 5A. We first evaluated the impact of 17f alone on MV4-11S and MV4-11R cell growth and showed that MV4-11R cells were more resistant to $17 \mathrm{f}$ treatment than MV4-11S cells (Figure 5B). Based on these data, $\mathrm{IC}_{50}$ values were found to be three-fold higher in MV4-11R than in MV11-4S cells $(10.79 \pm 3.2$ vs. $3.55 \pm 0.47)$.

\section{6. $17 f$ Sensitizes MV4-11R Cells to Ara-C Treatment}

We then analyzed the effects of $17 \mathrm{f}$ on MV4-11S and MV4-11R cell growth in the presence of Ara-C using trypan blue dye exclusion (Figure 6A) and MTT assays (Figure 6B). Addition of 17f significantly enhanced the growth inhibition and cytotoxic effect of Ara-C in MV4-11S cells. Importantly, 17f greatly reduced the growth of resistant MV4-11R cells cultured with Ara-C in a concentration-dependent fashion. This growth inhibition was already observed with $1 \mu \mathrm{M}$, a concentration that did not affect the growth of MV4-11R cells cultured in the absence of Ara-C. These data indicated that the addition of $17 \mathrm{f}$ overcomes the resistance of MV4-11R cells to Ara-C. 
A

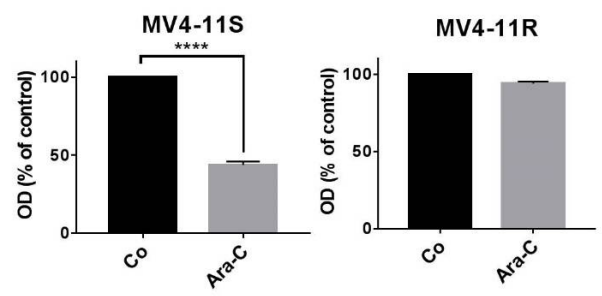

B

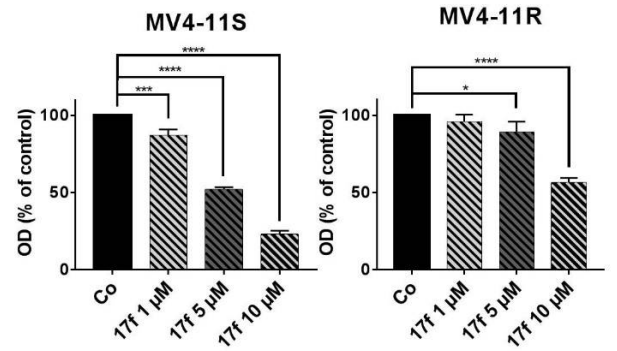

Figure 5. Effects of $17 \mathrm{f}$ on MV4-11S and MV4-11R cell growth (A) Ara-C-sensitive MV4-11 (MV4-11S) and Ara-C-resistant MV4-11 (MV4-11R) cells were treated with $1 \mu \mathrm{M}$ Ara-C or DMSO as control (Co) for $48 \mathrm{~h}$. Cell viability was then determined by MTT assays $(n=3$ in triplicates, data are mean \pm SD, **** $p<0.0001$; one-sample $t$-test). (B) MV4-11S and MV4-11R cells were treated or not (Co) with increasing concentrations of $17 \mathrm{f}$ during $48 \mathrm{~h}$. Cell viability was determined by MTT assays ( $n=3$ in triplicates, data are mean $\pm \mathrm{SD},{ }^{* *} p<0.01,{ }^{* * *} p<0.001,{ }^{* * *} p<0.0001$; one-sample $t$-test).

A

MV4-11S

MV4-11R
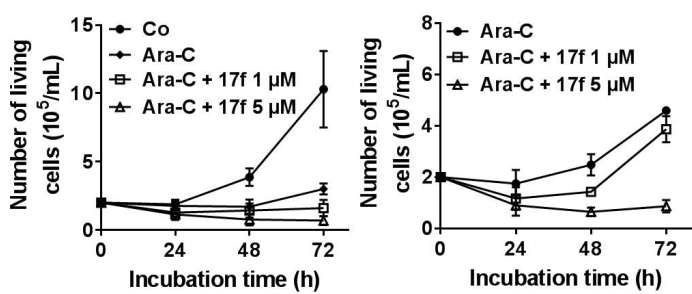

B

MV4-11S

MV4-11R

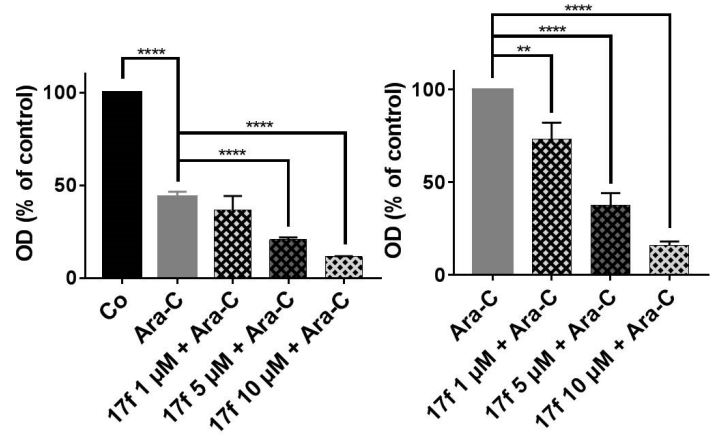

Figure 6. $17 \mathrm{f}$ relieves the resistance of MV4-11R cells to ARA-C treatment. (A) MV4-11S or MV4-11R cells were treated with Ara-C or not (Co) with or without 17f. Growth kinetics were determined by Trypan blue dye exclusion assays ( $n=3$ in triplicates, data are mean \pm SD). (B) MV4-11S or MV4-11R cells were treated with Ara-C or not (Co) with or without $17 \mathrm{f}$ for $48 \mathrm{~h}$. Cell viability was determined by MTT assays ( $\mathrm{n}=3$ in triplicates, data are mean $\pm \mathrm{SD},{ }^{*} p<0.05,{ }^{* *} p<0.01,{ }^{* * *} p<0.0001$; one-sample $t$-test). 


\subsection{7f Triggers Apoptosis, Cell Cycle Arrest and Inhibition of STAT5B Expression in MV4-11R Cells}

We then evaluated the effects of $17 \mathrm{f}$ on apoptosis and the cell cycle in MV4-11R cells. A significant increase in apoptotic cells was observed (Figure 7A) only after treatment with $5 \mu \mathrm{M}$ 17f, while the addition of $1 \mu \mathrm{M}$ was enough to enhance the number of cells in the $\mathrm{G}_{0}$ phase of the cell cycle (Figure $7 \mathrm{~B}$ ). These results indicated that the growth-suppressive properties of $17 \mathrm{f}$ primarily affect the cell cycle in MV4-11R cells and apoptosis at higher concentrations. We then asked whether $17 \mathrm{f}$ interferes with STAT5 signaling in Ara-C-resistant AML cells and analyzed the impact of $17 \mathrm{f}$ on phosphorylation and expression of STAT5 in MV4-11R cells. In the absence of Ara-C, the level of STAT5 phosphorylation was slightly enhanced in MV4-11R cells (Figure S5C,D). The addition of $17 \mathrm{f}$ with or without Ara-C inhibited STAT5 expression in MV4-11R cells (Figure 7C and Figures S2B and S3C). Likewise, STAT5B expression was reduced after treatment with $17 \mathrm{f}$ alone or with Ara-C in resistant cells (Figure 7D).

A

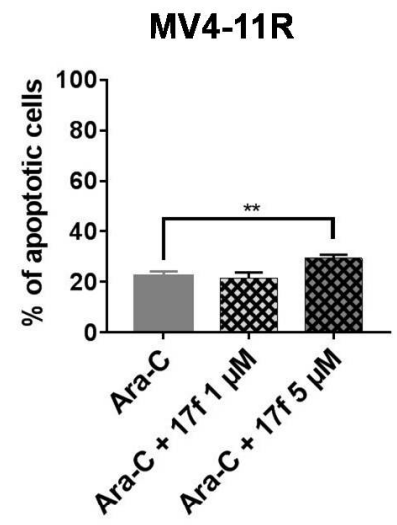

C

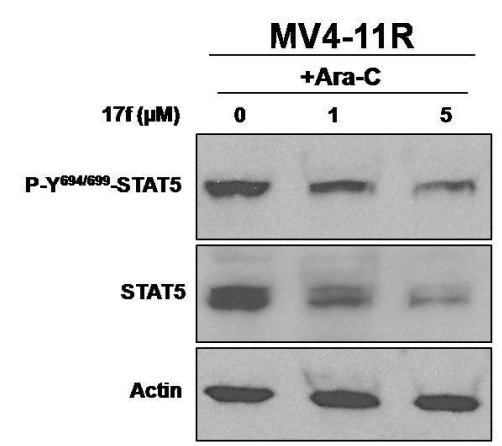

B

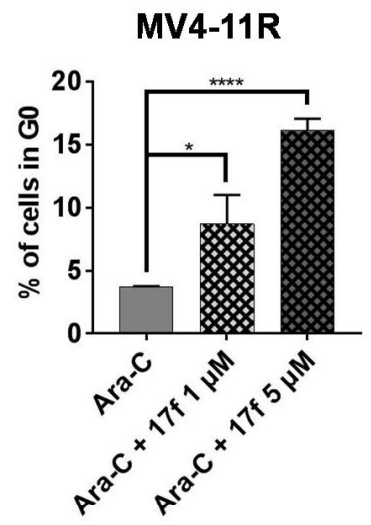

D

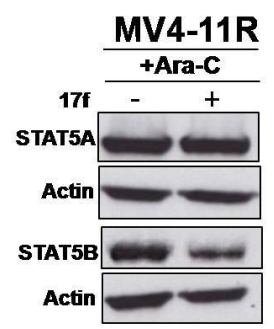

Figure 7. $17 \mathrm{f}$ promotes apoptosis, cell cycle arrest and inhibition of STAT5B protein expression in MV4-11R cells. (A) Flow cytometry histogram of MV4-11R cells cultured for $48 \mathrm{~h}$ with Ara-C and $17 \mathrm{f}$ or Ara-C and DMSO as control. Cells were stained with anti-annexin V coupled with FITC and with 7-AAD to determine the percentages of apoptotic cells $(n=3$ in triplicates, data are mean $\pm \mathrm{SD}$, ** $p<0.01$ ). (B) MV4-11R cells treated for $48 \mathrm{~h}$ with Ara-C and $17 \mathrm{f}$ or Ara-C and DMSO as control were stained with 7-AAD and an Alexa Fluor 488-conjugated anti-Ki67 antibody. Cell cycle phase distributions were then estimated by flow cytometry. The histogram presents the percentage of cells in the $\mathrm{G}_{0}$ phase ( $n=3$ in triplicates, data are mean $\pm \mathrm{SD},{ }^{*} p<0.05,{ }^{* * *} p<0.001$ ). (C) Protein extracts from MV4-11R cells treated with Ara-C and 17f or Ara-C and DMSO for $24 \mathrm{~h}$ were analyzed by immunoblotting to detect P-Y694/699-STAT5 and STAT5 protein expression $(n=2)$. Actin served as the loading control. (D) Expression of STAT5A and STAT5B proteins in MV4-11R cells treated or not with $17 \mathrm{f}(5 \mu \mathrm{M})$ was also analyzed by western blot $(n=2)$. 


\section{8. $17 f$ Inhibits Expression of Oncogenic STAT5B ${ }^{\mathrm{N} 642 \mathrm{H}}$ Mutant}

Gain of function mutations of STAT5B have been described in hematopoietic malignancies. The recurrent hotspot mutation $\mathrm{N} 642 \mathrm{H}$ has been identified in $\mathrm{T}$ cell leukemia and lymphomas and the STAT5 $\mathrm{B}^{\mathrm{N} 642 \mathrm{H}}$ mutant was shown to induce T cell neoplasia in transgenic mice [24-27]. We therefore tested the ability of $17 \mathrm{f}$ to inhibit STAT5B $\mathrm{B}^{\mathrm{N} 642 \mathrm{H}}$ expression and growth of hematopoietic cells transformed by this mutant. For this purpose, we used $\mathrm{Ba} / \mathrm{F} 3$ cells expressing flag-tagged STAT5B ${ }^{\mathrm{N} 642 \mathrm{H}}$ or flag-tagged wild-type STAT5B (wtSTAT5B) as control [27]. We found that Ba/F3-STAT5B ${ }^{\mathrm{N} 642 \mathrm{H}}$ cells were more sensitive to $17 \mathrm{f}$ treatment than control Ba/F3-wtSTAT5B cells (Figure 8A). We then addressed whether STAT5 ${ }^{\mathrm{N} 642 \mathrm{H}}$ expression was impacted by $17 \mathrm{f}$ and showed that $17 \mathrm{f}$ reduces expression of this mutant in $\mathrm{Ba} / \mathrm{F} 3$ cells but does not affect wtSTAT5B or endogenous STAT5A expression after $24 \mathrm{~h}$ treatment (Figure 8B).

A

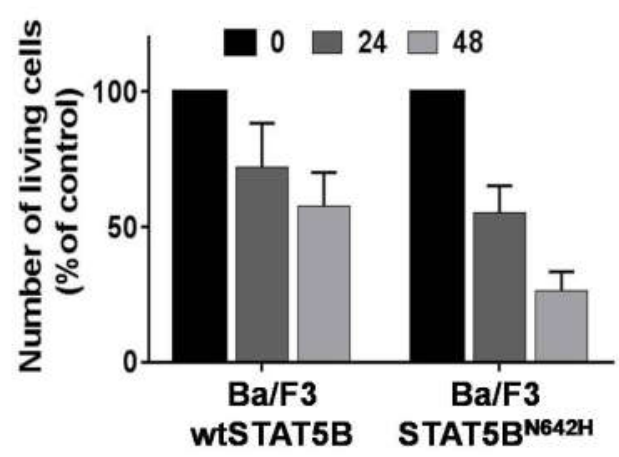

B

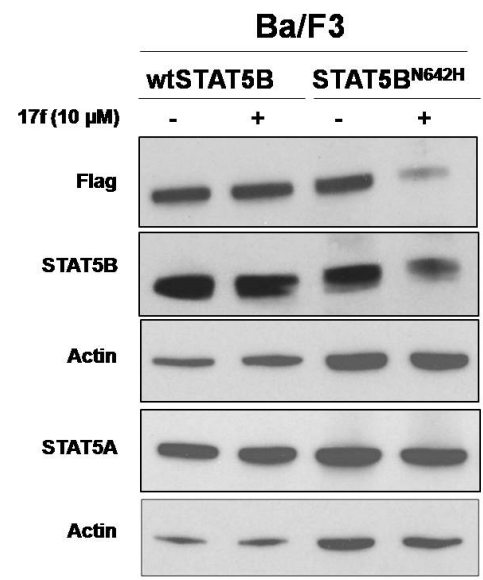

Figure 8. $17 \mathrm{f}$ inhibits STAT5 $\mathrm{B}^{\mathrm{N} 642 \mathrm{H}}$ activity and expression in Ba/F3 cells. (A) Cells were treated or not with $17 \mathrm{f}(10 \mu \mathrm{M})$. Growth were then determined by Trypan blue dye exclusion assays at the indicated times ( $n=5$ in triplicates, data are mean \pm SD). (B) Protein extracts from MV4-11R cells treated with $17 \mathrm{f}$ for $24 \mathrm{~h}$ were analyzed by immunoblotting to detect flag-tagged $w \mathrm{tSTAT} 5 \mathrm{~B}, \mathrm{STAT} 5 \mathrm{~B}^{\mathrm{N} 642 \mathrm{H}}$ and endogenous STAT5A/STAT5B protein expression $(n=2)$. Actin served as the loading control.

\section{Discussion}

The development of pharmacological inhibitors targeting the JAK/STAT pathway has been the subject of intense investigation during the last decade. Among the STAT family members, STAT5 proteins are now recognized as important therapeutic targets in hematologic malignancies and also in certain solid tumors [28]. Distinct pharmacological compounds that directly or indirectly affect STAT5 activity and leukemia cell growth have been used or developed during these last years. We recently synthesized and discovered a new compound (17f) that inhibits STAT5 phosphorylation and transcriptional activity in various CML and AML cells, without detectable effects on other signal 
transduction molecules, such, as STAT3 and the protein kinases ERK1/2 and AKT [23]. We also demonstrated that $17 \mathrm{f}$ strongly reduces the growth of $\mathrm{CML}$ and $\mathrm{AML}$ cells with $\mathrm{EC}_{50}$ values below $10 \mu \mathrm{M}$ close to $\mathrm{EC}_{50}$ values obtained with the STAT5 inhibitor pimozide (unpublished data) indicating that $17 \mathrm{f}$ as pimozide targets myeloid leukemia cells addicted to STAT5 signaling (see also Figure S1 for $17 \mathrm{f}$ and pimozide structures). In this study, we bring evidences that $17 \mathrm{f}$ also relieves the resistance of CML and AML cells to IM and Ara-C, respectively. Interestingly, we found that the concentrations of $17 \mathrm{f}$ required to restore the response to IM and Ara-C in resistant leukemic cells were much lower than $\mathrm{EC}_{50}$ values obtained for each resistant cell type. Indeed, inhibition of cell growth was already observed with $1 \mu \mathrm{M}$ when combined with IM or Ara-C while $\mathrm{EC}_{50}$ values obtained for $17 \mathrm{f}$ compound alone were greater than $10 \mu \mathrm{M}$ in these resistant cells. Depletion of IM or Ara-C in resistant cells might explain changes in the growth inhibitory effects of 17f. Indeed, we observed that the removal of IM strongly increases the phosphorylation of STAT5 in K562R cells. In these conditions, P-Y-STAT5 protein levels remain much higher in K562R cells after $17 \mathrm{f}$ treatment than in treated K562S cells, which are sensitive to lower concentrations of $17 \mathrm{f}$. These data are in close agreement with a previously published study showing that high STAT5 levels mediate IM resistance in CML cells [8]. Although the removal of Ara-C results in a slight increase in STAT5 phosphorylation, the resistance of MV4-11R cells to this drug is not directly linked to overactivated STAT5. ERK1/2 and AKT kinases that also play a crucial role in cell survival, are involved in the resistance of MV4-11 cells to Ara-C [29]. It is then likely that Ara-C depletion may overexpress or overactivate these survival pathways in resistant MV4-11 cells. Whatever the resistance mechanism associated or not with STAT5 signaling, our data suggest that combination treatments with a STAT5 inhibitor might efficiently eliminate resistant CML and AML cells.

While $17 \mathrm{f}$ alone inhibited STAT5 phosphorylation in IM-depleted K562R cells, it decreased STAT5 expression in Ara-C-depleted MV4-11R cells. Importantly, combination treatments reduced expression of STAT5 in both resistant leukemic cells. The mechanisms involved in this downregulation remain unknown but are not associated with changes in STAT5A and STAT5B gene expression and specifically affect STAT5B protein. Importantly, we also demonstrated that $17 \mathrm{f}$ inhibits expression of STAT5B $\mathrm{B}^{\mathrm{N} 642 \mathrm{H}}$ protein expression in transformed $\mathrm{Ba} / \mathrm{F} 3$ cells. STAT5 $\mathrm{B}^{\mathrm{N} 642 \mathrm{H}}$ is a driver mutation for $\mathrm{T}$ cell neoplasia and has been associated with aggressiveness, poor prognosis and an increased risk of relapse in $\mathrm{T}$ cell leukemia-lymphoma patients [24-27]. In addition to myeloid leukemia, $17 \mathrm{f} \mathrm{might} \mathrm{be} \mathrm{then} \mathrm{employed} \mathrm{to}$ target lymphoproliferative disorders and lymphomas addicted to STAT5B $\mathrm{B}^{\mathrm{N} 62 \mathrm{H}}$ signaling.

It is likely that $17 \mathrm{f}$ inhibits STAT5B expression via the ubiquitin/proteasome-dependent degradation of this protein. Indeed, STAT5 proteins were previously shown to be ubiquitinated and several ubiquitination sites have been identified in STAT5A and STAT5B protein sequences [30,31]. $\mathrm{Cbl}$, a well-known E3 ubiquitin ligase was found to interact with STAT5 and to induce its ubiquitination [30]. Moreover, cytokine-mediated STAT5 phosphorylation was enhanced in hematopoietic stem cells from $c-c b l$ knockout mice [32]. $17 \mathrm{f}$ alone or associated with IM or Ara-C might then promote ubiquitination and proteasomal degradation of STAT5B protein in resistant leukemic cells as well as in STAT5B ${ }^{\mathrm{N} 642 \mathrm{H}}$-expressing cells. In a similar vein, pimozide was shown to target USP1, a ubiquitin specific protease involved in the deubiquitination of transcription factors such as ID-1. Pimozide-mediated inhibition of USP-1 promotes ID1 degradation and inhibition of leukemic cell growth [12]. It is therefore conceivable that $17 \mathrm{f}$ activity is connected to $a$ proteasome regulatory network that controls STAT5B protein degradation. Alternatively, the combination of $17 \mathrm{f}$ and IM or Ara-C might also target chaperone molecules such as the heat shock proteins HSP90 or HSP70 proteins which were previously shown to regulate expression and/or stability of STAT5 [33,34]. The dual inhibition of BCR-ABL and HSP90 was shown to abrogate the growth of IM-resistant CML cells [35]. Furthermore, a key role of STAT5 has been demonstrated in the synergistic effects of FLT3 and HSP90 inhibitors in FLT3-ITD-expressing leukemic cells [36]. Importantly, HSP90 inhibitors not only target STAT5 but also overcome the resistance of AML cells to FLT3 inhibitors [37]. HSP70 was also found to induce STAT5 
expression and drug resistance in AML and CML cells and inhibition of STAT5 activity was sufficient to resensitize resistant leukemic cells to chemotherapy [34,38].

If the downregulation of STAT5A and STAT5B expression can occur via ubiquitin/proteasome-dependent protein degradation, the selective effect of $17 \mathrm{f}$ on STAT5B still remains unclear. Nevertheless, using a bacterial two-hybrid screening approach, we previously identified the tumor suppressor hTid1 as a specific binding partner of STAT5B [39]. hTid1 belongs to the DnaJ chaperone protein family, which contains the J domain, a highly conserved domain that binds to Hsp70. The DnaJ-Hsp70 complexes are involved in protein folding and protein degradation and hTid1 was shown to promote the ubiquitination and degradation of various cellular proteins including transcription factors [40]. We demonstrated that overexpression of hTid1 specifically suppresses STAT5B protein expression and the transforming potential of a constitutively active STAT5B variant (STAT5B1*6) in hematopoietic cells. $17 \mathrm{f}$ might then target specific effectors of STAT5B protein stability/degradation, a hypothesis that has yet to be experimentally tested.

Besides these potential mechanisms, the capacity of $17 \mathrm{f}$ to restore the sensitivity of resistant CML or AML cells to IM or Ara-C suggests that inhibitors targeting STAT5 expression would also benefit AML or CML patients who have developed resistance to chemotherapy. Accordingly, PPAR $\gamma$ agonists were shown to inhibit STAT5A and STAT5B gene expression and to synergize with IM to eradicate resistant CML stem cells [10]. Our findings suggest that targeting STAT5B protein is a promising therapeutic strategy to eradicate leukemic cells that acquired resistance to chemotherapeutic agents. This is also supported by previous works showing that STAT5B but not STAT5A plays a key role in BCR-ABL-induced leukemogenesis and in the sensitivity of CML cells to TKI treatment $[41,42]$. Recent studies indicated that STAT5 proteins also exert important non canonical functions in normal and cancer cells. For instance, unphosphorylated STAT5 (USTAT5: non phosphorylated on Y694/699 residues) were shown to be transcriptionally active in self-renewing hematopoietic stem cells and to promote leukemia/lymphoma cell survival [43,44]. Selective inhibitors that only block tyrosine phosphorylation and dimer formation might then be insufficient to fully abrogate STAT5 activity and resistance to chemotherapy. Herein, we showed that that inhibition of STAT5B expression elicited by $17 \mathrm{f}$ might unlock drug resistance in CML and AML cells. Using these promising data as a lead, we carried out a rational search for new derivatives of $17 \mathrm{f}$ with enhanced antileukemic activity. Modeling work was initiated to identify a pharmacophore that could help to optimize the development of $17 \mathrm{f}$ derivatives working in the nanomolar range. These new compounds could represent promising drugs to overcome chemotherapy resistance in leukemia or lymphomas.

\section{Materials and Methods}

\subsection{Cell Cultures and Reagents}

IM-sensitive (K562S) and IM-resistant (K562R) BCR-ABL ${ }^{+}$cells and MV4-11 cells were obtained from American Type Culture Collection (ATCC) and Deutsche Sammlung von Mikroorganismens und Zellkulturen (DSMZ), respectively, and maintained according to the supplier's recommendations. K562R and Ara-C-resistant MV4-11 (MV4-11R) cells were obtained after cultures of K562S and sensitive MV4-11 (MV4-11S) cells with increasing concentrations of IM and Ara-C (until $1 \mu \mathrm{M}$ ). $\mathrm{Ba} / \mathrm{F} 3-\mathrm{STAT5B} \mathrm{B}^{\mathrm{N} 642 \mathrm{H}}$ and Ba/F3-wtSTAT5B cells were previously described in [27]. All cell lines were cultured in RPMI 1640, with $10 \%$ fetal bovine serum, $2 \mathrm{mM}$ glutamine, $100 \mathrm{U} / \mathrm{mL}$ penicillin and $100 \mu \mathrm{g} / \mathrm{mL}$ streptomycin at $37{ }^{\circ} \mathrm{C}, 5 \% \mathrm{CO}_{2}$. Resistant cells were cultured with $1 \mu \mathrm{M}$ IM or Ara-C. IM was purchased from Selleckchem (Houston, TX, USA) and Ara-C from Sandoz France (Levallois-Perret, France). Ba/F3-wtSTAT5B were cultured with IL-3. The synthesis of the $17 \mathrm{f} \mathrm{compound}$ was previously described in [23]. 


\subsection{Cell Proliferation Assays}

Cell viability and proliferation were studied using a MTT cell proliferation assay (Sigma-Aldrich, St Louis, MO, USA). Briefly, $2 \times 10^{4}$ leukemic cells were cultured in $100 \mu \mathrm{L}$ of RPMI medium in 96-well plates and treated with drugs for $48 \mathrm{~h}$. Cells were then incubated with $10 \mu \mathrm{L}$ of MTT working solution ( $5 \mathrm{~g} / \mathrm{L}$ of methylthiazolyldiphenyl-tetrazolium bromide) for $4 \mathrm{~h}$. Cells were lysed overnight at $37^{\circ} \mathrm{C}$ with $100 \mu \mathrm{L}$ of SDS $10 \%, \mathrm{HCl} 0.003 \%$. Optical density (OD) at $570 \mathrm{~nm}$ was then measured using a spectrophotometer CLARIOstar ${ }^{\circledR}$ (BMG Labtech, Offenburg, Germany). Living cells were also enumerated using the trypan blue dye exclusion method.

\subsection{Apoptosis and Cell Cycle Analysis}

Cells were washed with PBS, then stained $\left(10^{6}\right.$ cells $)$ in buffer containing FITC-annexin V and 7-amino-actinomycin D (7-AAD) (Beckmann Coulter, Fullerton, CA, USA) for 15 min at $4{ }^{\circ} \mathrm{C}$ and analyzed by flow cytometry (Becton Dickinson Accuri ${ }^{\mathrm{TM}}$ C 6 flow cytometer). For cell cycle analysis [45], cells were first incubated with fixing solution (PFA 2\%, Hepes 1\%, saponin $0.03 \%$ ) for $15 \mathrm{~min}$ and then in PFS permeabilization solution (PBS $1 \times$, SVF $10 \%$, saponin $0.03 \%$, Hepes $1 \%$ ). Cells were next stained for $30 \mathrm{~min}$ at room temperature with anti-Ki67-Alexa Fluor 488 monoclonal antibody or the corresponding isotype as control (Becton-Dickinson, Franklin Lakes, NJ, USA) before analysis by flow cytometry (Becton Dickinson Accuri ${ }^{\mathrm{TM}}$ C6 flow cytometer). The FlowJo ${ }^{\circledR}$ software (V10.1, BD Biosciences, Franklin Lakes, NJ, USA) was used to analyze data.

\subsection{Plasmids, Transfection and Luciferase Reporter Assays}

The $6 \times$ (STAT5)-TK-luc containing six tandem copies of the STAT5 binding site linked to the minimal TK-luciferase reporter gene and control TK-luc plasmids have been described elsewhere [46]. For transient transfection assays, cells were electroporated $(270 \mathrm{~V}, 950 \mu \mathrm{F})$ with the different constructs $(50 \mu \mathrm{g})$. Transfected cells were expanded for $24 \mathrm{~h}$ in medium and then treated for $48 \mathrm{~h}$. Cell extracts were then prepared in luciferase buffer according to the manufacturer's protocol (One Glo luciferase assay kit, Promega, Madison, WI, USA). Luciferase activities were measured in a luminometer CLARIOstar ${ }^{\circledR}$ (BMG Labtech, Offenburg, Germany).

\subsection{Western Blot}

Cells were suspended in Laemmli's $2 \times$ buffer (Bio-Rad, Hercules, CA, USA), separated on SDS/PAGE and blotted onto nitrocellulose membrane. Blots were incubated with the following

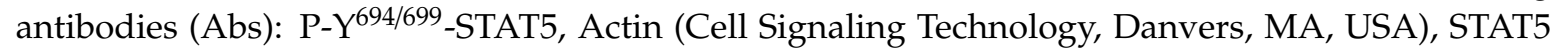
(BD Transduction Laboratories, Franklin Lakes, NJ, USA), STAT5A and STAT5B (Zymed/ThermoFisher Scientific, Waltham, MA, USA). Membranes were developed with the ECL chemiluminescence detection system (GE Healthcare, Little Chalfont Buckinghamshire, UK) using specific peroxidase (HRP) conjugated to rabbit or mouse IgG antibodies (Cell Signaling Technology).

\subsection{P-Y694/699-STAT5 Flow Cytometry Analysis}

Cells were washed in PBS and incubated with a fixing solution PFA 4\% for $15 \mathrm{~min}$ at room temperature. The first permeabilization solution PBS/Triton X-100 $0.2 \%$ was then added and incubated for $30 \mathrm{~min}$ at $37^{\circ} \mathrm{C}$. After being washed with PBS/BSA $0.5 \%$, cells were suspended with the second permeabilization solution PBS/MeOH $50 \%$ and incubated for $10 \mathrm{~min}$ on ice. Cells were then stained with anti P-Y ${ }^{694 / 699}$-STAT5 antibodies or the corresponding isotype as control (BD Biosciences, NJ, USA) for $30 \mathrm{~min}$ at room temperature before analysis by flow cytometry (FACS Canto II, BD Biosciences).

\section{7. $q R T-P C R$ Analysis}

RNA samples were reverse-transcribed using the SuperScript ${ }^{\circledR}$ VILO cDNA synthesis kit (Invitrogen, Carlsbad, CA, USA) as recommended by the supplier. The resulting cDNAs were used for 
quantitative real-time PCR (qRT-PCR). PCR primers (PIM1: for 5'-TTTCGAGCATGACGAAGAGA-3', rev 5'-GGGCCAAGCACCATCTAAT-3'; CISH: 5'- AGCCAAGACCTTCTCCTACCTT-3' r rev 5'-TGGCATCTTCTGCAGGTGT-3'; STAT5A: for 5'-TCCCTATAACATGTACCCACA-3', rev

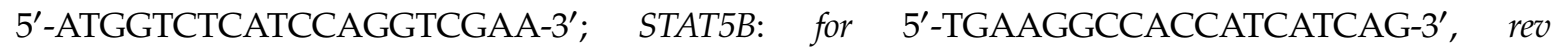
5'-TGTTCAAGATCTCGCCACTG-3') were designed with the ProbeFinder software (Roche Applied Sciences, Basel, Switzerland) and used to amplify the RT-generated cDNAs. qRT-PCR analyses were performed on the Light Cycler 480 thermocycler II (Roche). GAPDH (glyceraldehyde-3-phosphate dehydrogenase), ACTB (actin beta) and RPL13A were used as reference genes for normalization of qRT-PCR experiments. Each reaction condition was performed in triplicate. Relative gene expression was analyzed using the $2^{-\Delta \Delta C t}$ method [47].

\section{Conclusions}

In summary, this work shows for the first time that inhibition of STAT5B expression might be a promising targeting strategy to bypass the resistance of CML and AML cells to TKI or conventional chemotherapeutic agents. Investigations to elucidate the mechanisms involved in STAT5B downregulation induced by these combination therapies might help to design new inhibitors that specifically target cancer cells addicted to oncogenic STAT5B signaling.

Supplementary Materials: The following supplementary figures are available online at http://www.mdpi.com/ 2072-6694/11/12/2043/s1, Figure S1: Pimozide and 17f structures, Figure S2: Original western blot, Figure S3: Quantification of Western Blot data. Figure S4: Flow cytometry analysis of P-Y-STAT5 in K562S and K562R cells. Figure S5: Effects of 17f on P-Y-STAT5/STAT5 expression in IM-depleted K562R and Ara-C-depleted MV4-11R cells.

Author Contributions: Conceptualization, M.B.-B., G.P. and F.G.; Formal analysis, M.B.-B. and F.G.; Funding acquisition, G.P. and F.G.; Investigation, M.B.-B., M.D., N.V., M.P. and L.J.; Methodology, M.B.-B., M.D., N.V., M.P. and L.J.; Project administration, G.P. and F.G.; Resources, G.P. and F.G.; Supervision, G.P.; Validation, M.B.-B., M.D., N.V., M.P., F.M., G.P. and F.G.; Visualization, F.G.; Writing—original draft, M.B.-B., G.P. and F.G.; Writing-review \& editing, M.D., N.V., L.J., F.M., M.-C.V.-M. and O.H.

Funding: This study was supported by FRM (grant number: DCM20181039564), CNRS, Ligue Contre le Cancer and University of Tours. MB-B was supported by the ARC foundation and FRM.

Acknowledgments: We would like to thank Emmanuel Pecnard, Farah Kouzi and Elodie Coste for technical assistance; Christina Maria Wagner and Heidi A. Neubauer for providing Ba/F3STAT5B ${ }^{\text {N642H }}$ and $\mathrm{Ba} / \mathrm{F} 3 w \mathrm{tSTAT5B}$ cells.

Conflicts of Interest: The authors declare no conflict of interest.

\section{References}

1. Bunting, K.D. STAT5 signaling in normal and pathologic hematopoiesis. Front. Biosci. 2007, 12, $2807-2820$. [CrossRef] [PubMed]

2. Hoelbl, A.; Schuster, C.; Kovacic, B.; Zhu, B.; Wickre, M.; Hoelzl, M.A.; Fajmann, S.; Grebien, F.; Warsch, W.; Stengl, G.; et al. Stat5 is indispensable for the maintenance of Bcr/abl-positive leukemia. Eur. Mol. Biol. Organ. Mol. Med. 2010, 2, 98-110.

3. Ye, D.; Wolff, N.; Li, L.; Zhang, S.; Ilaria, R.L., Jr. STAT5 signaling is required for the efficient induction and maintenance of CML in mice. Blood 2006, 107, 4917-4925. [CrossRef] [PubMed]

4. Mizuki, M.; Fenski, R.; Halfter, H.; Matsumura, I.; Schmidt, R.; Müller, C.; Grüning, W.; Kratz-Albers, K.; Serve, S.; Steur, C.; et al. Flt3 mutations from patients with acute myeloid leukemia induce transformation of 32D cells mediated by the Ras and STAT5 pathways. Blood 2000, 96, 3907-3914. [CrossRef]

5. Chomel, J.C.; Bonnet, M.L.; Sorel, N.; Sloma, I.; Bennaceur-Griscelli, A.; Rea, D.; Legros, L.; Marfaing-Koka, A.; Bourhis, J.H.; Ame, S.; et al. Leukemic stem cell persistence in chronic myeloid leukemia patients in deep molecular response induced by tyrosine kinase inhibitors and the impact of therapy discontinuation. Oncotarget 2016, 7, 35293-35301. [CrossRef]

6. Gambacorti-Passerini, C.B.; Gunby, R.H.; Piazza, R.; Galietta, A.; Rostagno, R.; Scapozza, L. Molecular mechanisms of resistance to imatinib in Philadelphia-chromosome-positive leukaemias. Lancet Oncol. 2003, 4, 75-85. [CrossRef] 
7. Cumaraswamy, A.A.; Todic, A.; Resetca, D.; Minden, M.D.; Gunning, P.T. Inhibitors of Stat5 protein signaling. Med. Chem. Commun. 2012, 3, 22-27. [CrossRef]

8. Warsch, W.; Kollmann, K.; Eckelhart, E.; Fajmann, S.; Cerny-Reiterer, S.; Hölbl, A.; Gleixner, K.V.; Dworzak, M.; Mayerhofer, M.; Hoermann, G.; et al. High STAT5 levels mediate imatinib resistance and indicate disease progression in chronic myeloid leukemia. Blood 2011, 117, 3409-3420. [CrossRef]

9. Warsch, W.; Grundschober, E.; Berger, A.; Gille, L.; Cerny-Reiterer, S.; Tigan, A.-S.; Hoelbl-Kovacic, A.; Valent, P.; Moriggl, R.; Sexl, V. STAT5 triggers BCR-ABL1 mutation by mediating ROS production in chronic myeloid leukemia. Oncotarget 2012, 3, 1669-1687. [CrossRef]

10. Prost, S.; Relouzat, F.; Spentchian, M.; Ouzegdouh, Y.; Saliba, J.; Massonnet, G.; Beressi, J.P.; Verhoeyen, E.; Raggueneau, V.; Maneglier, B.; et al. Erosion of the chronic myeloid leukemia stem cell pool by PPAR $\gamma$ agonists. Nature 2015, 525, 380-383. [CrossRef]

11. Nelson, E.A.; Walker, S.R.; Weisberg, E.; Bar-Natan, M.; Barrett, R.; Gashin, L.B.; Terrell, S.; Klitgaard, J.L.; Santo, L.; Addorio, M.R.; et al. The STAT5 inhibitor pimozide decreases survival of chronic myelogenous leukemia cells resistant to kinase inhibitors. Blood 2011, 117, 3421-3429. [CrossRef] [PubMed]

12. Mistry, H.; Hsieh, G.; Buhrlage, S.J.; Huang, M.; Park, E.; Cuny, G.D.; Galinsky, I.; Stone, R.M.; Gray, N.S.; D'Andrea, A.D.; et al. Small-molecule inhibitors of USP1 target ID1 degradation in leukemic cells. Mol. Cancer Ther. 2013, 12, 2651-2662. [CrossRef] [PubMed]

13. Nam, S.; Scuto, A.; Yang, F.; Chen, W.; Park, S.; Yoo, H.S.; Konig, H.; Bhatia, R.; Cheng, X.; Merz, K.H.; et al. Indirubin derivatives induce apoptosis of chronic myelogenous leukemia cells involving inhibition of Stat5 signaling. Mol. Oncol. 2012, 6, 276-283. [CrossRef] [PubMed]

14. Page, B.D.; Khoury, H.; Laister, R.C.; Fletcher, S.; Vellozo, M.; Manzoli, A.; Yue, P.; Turkson, J.; Minden, M.D.; Gunning, P.T. Small molecule STAT5-SH2 domain inhibitors exhibit potent antileukemia activity. J. Med. Chem. 2012, 55, 1047-1055. [CrossRef]

15. Cumaraswamy, A.A.; Lewis, A.M.; Geletu, M.; Todic, A.; Diaz, D.B.; Cheng, X.R.; Brown, C.E.; Laister, R.C.; Muench, D.; Kerman, K.; et al. Nanomolar-potency small molecule inhibitor of STAT5 protein. Am. Chem. Soc. Med. Chem. Lett. 2014, 5, 1202-1206. [CrossRef]

16. Elumalai, N.; Berg, A.; Rubner, S.; Blechschmidt, L.; Song, C.; Natarajan, K.; Matysik, J.; Berg, T. Rational development of Stafib-2: A selective, nanomolar inhibitor of the transcription factor STAT5b. Sci. Rep. 2017, 7, 819. [CrossRef]

17. Wingelhofer, B.; Maurer, B.; Heyes, E.C.; Cumaraswamy, A.A.; Berger-Becvar, A.; de Araujo, E.D.; Orlova, A.; Freund, P.; Ruge, F.; Park, J.; et al. Pharmacologic inhibition of STAT5 in acute myeloid leukemia. Leukemia 2018, 32, 1135-1146. [CrossRef]

18. Prost, S.; Le Dantec, M.; Augé, S.; Le Grand, R.; Derdouch, S.; Auregan, G.; Déglon, N.; Relouzat, F.; Aubertin, A.M.; Maillere, B.; et al. Human and simian immunodeficiency viruses deregulate early hematopoiesis through a Nef/PPAR $\gamma /$ STAT5 signaling pathway in macaques. J. Clin. Investig. 2008, 118, 1765-1775. [CrossRef]

19. Liu, H.; Zang, C.; Fenner, M.H.; Liu, D.; Possinger, K.; Koeffler, H.P.; Elstner, E. Growth inhibition and apoptosis in human Philadelphia chromosome-positive lymphoblastic leukemia cell lines by treatment with the dual PPAR $\alpha / \gamma$ ligand TZD18. Blood 2006, 107, 3683-3692. [CrossRef]

20. Bertz, J.; Zang, C.; Liu, H.; Wächter, M.; Possinger, K.; Koeffler, H.P.; Elstner, E. Compound 48, a novel dual PPAR $\alpha / \gamma$ ligand, inhibits the growth of human CML cell lines and enhances the anticancer-effects of imatinib. Leuk. Res. 2009, 33, 686-692. [CrossRef]

21. Parmenon, C.; Guillard, J.; Caignard, D.-H.; Hennuyer, N.; Staels, B.; Audinot-Bouchez, V.; Boutin, J.A.; Dacquet, C.; Ktorza, A.; Viaud-Massuard, M.C. 4,4-Dimethyl-1,2,3,4-Tetrahydroquinoline-Based PPAR $\alpha / \gamma$ agonists. Part I: Synthesis and pharmacological evaluation. Bioorg. Med. Chem. Lett. 2008, 18, 1617-1622. [CrossRef]

22. Parmenon, C.; Guillard, J.; Caignard, D.-H.; Hennuyer, N.; Staels, B.; Audinot-Bouchez, V.; Boutin, J.A.; Dacquet, C.; Ktorza, A.; Viaud-Massuard, M.C. 4,4-Dimethyl-1,2,3,4-Tetrahydroquinoline-Based PPAR $\alpha / \gamma$ agonists. Part II: Synthesis and pharmacological evaluation of oxime and acidic head group structural variations. Bioorg. Med. Chem. Lett. 2009, 19, 2683-2687. [CrossRef]

23. Juen, L.; Brachet-Botineau, M.; Parmenon, C.; Bourgeais, J.; Hérault, O.; Gouilleux, F.; Viaud-Massuard, M.C.; Prié, G. New inhibitor targeting signal transducer and activator of transcription 5 (STAT5) signaling in myeloid leukemias. J. Med. Chem. 2017, 60, 6119-6136. [CrossRef] 
24. Kontro, M.; Kuusanmäki, H.; Eldfors, S.; Burmeister, T.; Andersson, E.I.; Bruserud, O.; Brümmendorf, T.H.; Edgren, H.; Gjertsen, B.T.; Itälä-Remes, M.; et al. Novel activating STAT5B mutations as putative drivers of T-cell acute lymphoblastic leukemia. Leukemia 2014, 28, 1738-1742. [CrossRef]

25. Bandapalli, O.R.; Schuessele, S.; Kunz, J.B.; Rausch, T.; Stütz, A.M.; Tal, N.; Geron, I.; Gershman, N.; Izraeli, S.; Eilers, J.; et al. The activating STAT5B N642H mutation is a common abnormality in pediatric T-cell acute lymphoblastic leukemia and confers a higher risk of relapse. Haematologica 2014, 99, 188-192. [CrossRef]

26. Nicolae, A.; Xi, L.; Pittaluga, S.; Abdullaev, Z.; Pack, S.D.; Chen, J.; Waldmann, T.A.; Jaffe, E.S.; Raffeld, M. Frequent STAT5B mutations in $\gamma \delta$ hepatosplenic T-cell lymphomas. Leukemia 2014, 28, 2244-2248. [CrossRef]

27. Pham, H.T.T.; Maurer, B.; Prchal-Murphy, M.; Grausenburger, R.; Grundschober, E.; Javaheri, T.; Nivarthi, H.; Boersma, A.; Kolbe, T.; Elabd, M.; et al. STAT5BN642H is a driver mutation for T cell neoplasia. J. Clin. Investig. 2018, 128, 387-401. [CrossRef]

28. Liao, Z.; Nevalainen, M.T. Targeting transcription factor Stat5a/b as a therapeutic strategy for prostate cancer. Am. J. Transl. Res. 2011, 3, 133-138.

29. Ko, Y.C.; Hu, C.Y.; Liu, Z.H.; Tien, H.F.; Ou, D.L.; Chien, H.F.; Lin, L.I. Cytarabine-Resistant FLT3-ITD Leukemia Cells are Associated with TP53 Mutation and Multiple Pathway Alterations-Possible Therapeutic Efficacy of Cabozantinib. Int. J. Mol. Sci. 2019, 20, 1230. [CrossRef]

30. Goh, E.L.; Zhu, T.; Leong, W.Y.; Lobie, P.E. c-Cbl is a negative regulator of GH-stimulated STAT5-mediated transcription. Endocrinology 2002, 143, 3590-3603. [CrossRef]

31. Chen, Y.; Dai, X.; Haas, A.L.; Wen, R.; Wang, D. Proteasome-dependent down-regulation of activated Stat5A in the nucleus. Blood 2006, 108, 566-574. [CrossRef]

32. Rathinam, C.; Thien, C.B.; Langdon, W.Y.; Gu, H.; Flavell, R.A. The E3 ubiquitin ligase c-Cbl restricts development and functions of hematopoietic stem cells. Genes Dev. 2008, 22, 992-997. [CrossRef]

33. Moulick, K.; Ahn, J.H.; Zong, H.; Rodina, A.; Cerchietti, L.; Gomes DaGama, E.M.; Caldas-Lopes, E.; Beebe, K.; Perna, F.; Hatzi, K.; et al. Affinity-based proteomics reveal cancer-specific networks coordinated by Hsp90. Nat. Chem. Biol. 2011, 7, 818-826. [CrossRef]

34. Guo, F.; Sigua, C.; Bali, P.; George, P.; Fiskus, W.; Scuto, A.; Annavarapu, S.; Mouttaki, A.; Sondarva, G.; Wei, S.; et al. Mechanistic role of heat shock protein 70 in Bcr-Abl-mediated resistance to apoptosis in human acute leukemia cells. Blood 2005, 105, 1246-1255. [CrossRef]

35. Wu, L.; Yu, J.; Chen, R.; Liu, Y.; Lou, L.; Wu, Y.; Huang, L.; Fan, Y.; Gao, P.; Huang, M.; et al. Dual inhibition of $\mathrm{Bcr}-\mathrm{Abl}$ and Hsp90 by C086 potently inhibits the proliferation of imatinib-resistant CML cells. Clin. Cancer Res. 2015, 21, 833-843. [CrossRef]

36. Yao, Q.; Nishiuchi, R.; Kitamura, T.; Kersey, J.H. Human leukemias with mutated FLT3 kinase are synergistically sensitive to FLT3 and Hsp90 inhibitors: The key role of the STAT5 signal transduction pathway. Leukemia 2005, 19, 1605-1612. [CrossRef]

37. Katayama, K.; Noguchi, K.; Sugimoto, Y. Heat shock protein 90 inhibitors overcome the resistance to Fms-like tyrosine kinase 3 inhibitors in acute myeloid leukemia. Oncotarget 2018, 9, 34240-34258. [CrossRef]

38. Pocaly, M.; Lagarde, V.; Etienne, G.; Ribeil, J.A.; Claverol, S.; Bonneu, M.; Moreau-Gaudry, F.; Guyonnet-Duperat, V.; Hermine, O.; Melo, J.V.; et al. Overexpression of the heat-shock protein 70 is associated to imatinib resistance in chronic myeloid leukemia. Leukemia 2007, 21, 93-101. [CrossRef]

39. Dhennin-Duthille, I.; Nyga, R.; Yahiaoui, S.; Gouilleux-Gruart, V.; Régnier, A.; Lassoued, K.; Gouilleux, F. The tumor suppressor hTid1 inhibits STAT5b activity via functional interaction. J. Biol. Chem. 2011, 286, 5034-5042. [CrossRef]

40. Bae, M.K.; Jeong, J.W.; Kim, S.H.; Kim, S.Y.; Kang, H.J.; Kim, D.M.; Bae, S.K.; Yun, I.; Trentin, G.A.; Rozakis-Adcock, M.; et al. Tid-1 interacts with the von Hippel-Lindau protein and modulates angiogenesis by destabilization of HIF-1 $\alpha$. Cancer Res. 2005, 65, 2520-2525. [CrossRef]

41. Schaller-Schönitz, M.; Barzan, D.; Williamson, A.J.; Griffiths, J.R.; Dallmann, I.; Battmer, K.; Ganser, A.; Whetton, A.D.; Scherr, M.; Eder, M. BCR-ABL affects STAT5A and STAT5B differentially. PLoS ONE 2014, 9, e97243. [CrossRef]

42. Kollmann, S.; Grundschober, E.; Maurer, B.; Warsch, W.; Grausenburger, R.; Edlinger, L.; Huuhtanen, J.; Lagger, S.; Hennighausen, L.; Valent, P.; et al. Twins with different personalities: STAT5B-but not STAT5A-has a key role in BCR/ABL-induced leukemia. Leukemia 2019, 33, 1583-1597. [CrossRef] 
43. Park, H.J.; Li, J.; Hannah, R.; Biddie, S.; Leal-Cervantes, A.I.; Kirschner, K.; Flores Santa Cruz, D.; Sexl, V.; Göttgens, B.; Green, A.R. Cytokine-induced megakaryocytic differentiation is regulated by genome-wide loss of a uSTAT transcriptional program. Eur. Mol. Biol. Organ. J. 2016, 35, 580-594. [CrossRef]

44. Nagy, Z.S.; Rui, H.; Stepkowski, S.M.; Karras, J.; Kirken, R.A. A preferential role for STAT5, not constitutively active STAT3, in promoting survival of a human lymphoid tumor. J. Immunol. 2006, 177, 5032-5040. [CrossRef]

45. Vignon, C.; Debeissat, C.; Georget, M.-T.; Bouscary, D.; Gyan, E.; Rosset, P.; Herault, O. Flow cytometric quantification of all phases of the cell cycle and apoptosis in a two-color fluorescence plot. PLoS ONE 2013, 7, e68425. [CrossRef]

46. Moriggl, R.; Gouilleux-Gruart, V.; Jähne, R.; Berchtold, S.; Gartmann, C.; Liu, X.; Hennighausen, L.; Sotiropoulos, A.; Groner, B.; Gouilleux, F. Deletion of the carboxyl-terminal transactivation domain of MGF-Stat5 results in sustained DNA binding and a dominant negative phenotype. Mol. Cell. Biol. 1996, 16, 5691-5700. [CrossRef]

47. Livak, K.J.; Schmittgen, T.D. Analysis of relative gene expression data using real-time quantitative PCR and the $2^{-\Delta \Delta C T}$ method. Methods 2001, 25, 402-408. [CrossRef]

(C) 2019 by the authors. Licensee MDPI, Basel, Switzerland. This article is an open access article distributed under the terms and conditions of the Creative Commons Attribution (CC BY) license (http://creativecommons.org/licenses/by/4.0/). 